\title{
Burrow architecture and turbative activity of the thalassinid shrimp Callianassa subterranea from the central North Sea
}

\author{
E. J. Stamhuis*, C. E. Schreurs, J. J. Videler \\ Dept of Marine Biology, University of Groningen, PO Box 14, 9750 AA Haren, The Netherlands
}

\begin{abstract}
The architecture and development of the burrows of the endobenthic shrimp Callianassa subterranea from the central North Sea were studied in sediment-filled containers and thin cuvettes in the laboratory. Three-dimensional burrows of 81 shrimps were used to describe the 3 -dimensional burrow architecture. In total, 41 shrimps made 2 -dimensional burrows in cuvettes tailored to their body widths. Development of 8 burrows over time was registered by regularly mapping burrow outlines and sediment surface levels. Excavation velocities and sediment expulsion rates were denved from changes in the burrow outlines and sediment surface levels on the maps. The total tunnel length increased at a rate of $23.4 \pm 6.0 \mathrm{~mm} \mathrm{~h}^{-1}$ during the initial stage of burrow development. The length increase levelled off during the completion of the first and second U-tubes to $5.6 \pm 1.8 \mathrm{~mm} \mathrm{~h}^{-1}$ Initial sediment expulsion rates up to $15.0 \mathrm{~cm}^{3} \mathrm{~d}^{-1}$ werc established. The average sediment expulsion rate was $1.080 \pm 0.096 \mathrm{~cm}^{3}$ $\mathrm{d}^{-1}$ Extrapolation to a yearly dry werght (dry $\left.w t\right)$ sediment turnover, including population density and water temperature effects, resulted in an estimate of $15.5 \pm 2.7 \mathrm{~kg}$ dry $w \mathrm{~m} \mathrm{~m}^{-2} \mathrm{yr}^{-1}$, equivalent to a $1.2 \mathrm{~cm}$ layer. Samples of burrow lining, expelled sediment and unprocessed sediment did not show changes in grain size distributions or organic content due to manipulation or processing by C. subterranea. Burrow development experiments carried out in enriched seawater systems did not reveal consistent effects of particulate organic matter (POM) on sediment expulsion rates or on the composition of processed or unprocessed sediment.
\end{abstract}

KEY WORDS: Thalassinidea - Callianassa subterranea Burrow architecture Bioturbation Burrowing

\section{INTRODUCTION}

Thalassinid shrimps characteristically create and inhabit burrows. Some species excavate hard substrate, but most species prefer sediments (Scott et al. 1988). The Callianassidae are almost completely confined to marine soft sediments (de Vaugelas 1985, Griffis \& Suchanek 1991). Resin casting techniques revealed a large variation in size and shape of callianassid burrows (Dworschak 1983, Atkinson \& Chapman 1984, Atkinson \& Nash 1985, 1990, Dworschak \& Pervesler 1988, Witbaard \& Duineveld 1989, Nickell \& Atkinson 1995, Rowden \& Jones 1995). Both size and

•E-mail: e.j.stamhuis@biol.rug.n! shape of the burrow, as well as burrowing activity, are assumed to be related to feeding habits of the inhabiting species (Thompson \& Pritchard 1969, Ott et al. 1976. Swinbanks \& Murray 1981, Mukai \& Koike 1984). Suchanek (1985) distinguished 3 major burrowing guilds in thalassinids, depending on specific feeding habits: (1) filter feeders, usually occupying permanent U- or Y-shaped burrows, (2) deposit feeders, which create complex branched tube-systems which are regularly changed, and (3) gardening species, inhabiting deep, relatively simple permanent burrows with chambers for gardening micro-organisms on debris. This classification was refined by Griffis \& Suchanek (1991), who distinguish 6 burrow types among 3 feeding guilds: deposit feeders, drift catchers and filter/suspension feeders. Nickell \& Atkinson 
(1995) distinguish 3 trophic modes in relation to thalassinid burrow morphology: deposit feeding, omnivorous scavenging and suspension feeding. Their classification is based on studies of resin casts of the burrows and on video recordings of the (feeding) behaviour of 3 species of thalassinids from sea lochs on the Scottish west coast: Callianassa subterranea, Jaxea nocturna and Upogebia stellata. These 3 species are assumed to represent the respective 3 trophic modes, though plasticity in the feeding mechanism is assumed in all 3 species

Callianassa subterranea spends more than $40 \%$ of its active time burrowing, excavating and processing sediment (Stamhuis et al. 1996). This is typical for a deposit feeder (de Vaugelas 1985, Suchanek 1985, Griffis \& Suchanek 1991, Rowden \& Jones 1995, Stamhuis et al. 1996). Witbaard \& Duineveld (1989) speculate that $C$. subterranea feeds on particulate organic matter (POM) from the overlying water which becomes trapped in the burrow after ventilation. They also do not exclude gardening. Nickell \& Atkinson (1995) suspect $C$. subterranea to be a facultative filter feeder, but no behavioural patterns related to filter feeding or gardening were detected during detailed studies of the behaviour of $C$. subterranea from the central North Sea (Stamhuis et al. 1996).

Studies on the burrowing process and burrow morphology of Callianassa subterranea have also not provided a coherent picture (Witbaard \& Duineveld 1989, Atkinson \& Nash 1990, Nickell \& Atkinson 1995, Rowden \& Jones 1995). Although there is reasonable consensus on the structure of the central network of tunnels and spherical chambers, disagreement remains on the burrow depth, the number of openings to the surface, and the structure and function of the more peripheral parts of the burrow. Rowden \& Jones (1995) suggest the sedimentary conditions to be a possible determining factor in burrow morphology, causing intra-specific burrow plasticity.

The central North Sea shows a high abundance of Callianassa subterranea, with densities up to more than 50 ind. $\mathrm{m}^{-2}$ in the Oyster Grounds and near the Frisian Front (Witbaard \& Duineveld 1989, Rowden \& Jones 1994). The high silt content in this area (Creutzberg et al. 1984, de Wilde et al. 1984) is perhaps an advantage in burrow construction.

The present study concentrates on clarifying burrow architecture and burrow development of Callianassa subterranea of the central North Sea. Turbative activity, expressed as burrowing velocities and sediment expulsion rates, and the effects of burrowing on the sediment composition are quantified. The effect of POM enrichment on burrowing is evaluated. Relationships between burrow architecture and feeding mode in C. subterranea are discussed.

\section{METHODS}

Shrimps were collected from several locations at the southern border of the Oyster Grounds and at the Frisian Front, central North Sea, around $53^{\circ} 45^{\prime} \mathrm{N}$ and $4^{\circ} 30^{\prime}$ E. Sampling trips were made in October 1988, May 1989, October 1989, June 1990, October 1991 and September 1992 with the Dutch Research Vessels 'Aurelia' and 'Pelagia'. A boxcorer, penetrating the sediment to a depth of about $0.5 \mathrm{~m}$, was used for sampling. The cores were washed out on $2 \mathrm{~mm}$ mesh size sieves. Undamaged Callianassa subterranea with an estimated rostrum-to-telson length of at least $20 \mathrm{~mm}$ and ranging up to $50 \mathrm{~mm}$ were selected. Each shrimp was housed in a 0.5 I plastic jar containing a 3 to $4 \mathrm{~cm}$ thick layer of sediment covered with $2 \mathrm{~mm}$ mesh size netting to prevent escape. The jars were kept submerged in a large container which was continuously flushed with aerated seawater. In the laboratory the shrimp were separately put into sediment-filled plastic (polyethene) containers (5 or $10 \mathrm{l}$, open top) in running seawater systems, after being acclimated for 1 night to the conditions in the storage room. These conditions were about the same as the natural conditions: seawater temperature $\approx 12^{\circ} \mathrm{C}$, and salinity $\approx 30 \%$. Usually the shrimps started digging immediately and disappeared into the sediment within a few hours. For more details about collecting, transporting and keeping these animals, see Stamhuis et al. (1996).

The architecture of the burrows constructed by 81 shrimps in the storage containers was used to obtain a general description of the architecture of Callianassa subterranea burrows. The sediment content of each container was tipped on a table as a block. Careful dissection of these blocks allowed detailed observation of the burrows and provided insight about their architecture.

Burrow development, burrowing and sediment processing were studied by introducing individual Callianassa subterranea into sediment-filled $30 \times 30 \mathrm{~cm}$ perspex cuvettes with widths between 6 and $10 \mathrm{~mm}$, depending on the corresponding body width of the specimen. The removable back panels of the cuvettes were roughened on the inner side to prevent burrow collapse due to the sliding of sediment. The cuvettes were stored vertically, submerged in seawater aquaria. Usually shrimps started digging immediately after introduction, and established the main part of the (2-dimensional) burrow within 3 wk. The shrimps were visible throughout the burrow and the burrowing process could be studied by placing the transparent cuvettes against the front window of the aquarium. Over a period of almost $4 \mathrm{yr}_{1} 41$ animals constructed complete burrows in the cuvettes. The burrowing process was observed in each case and photographs of 
the burrows were taken. In 5 cases, the development of the burrow was studied by drawing the burrow outlines on overhead-projector transparencies at time intervals of a few hours to a few days for 2 to 3 wk after introduction of the shrimps to the cuvettes. Burrowing velocities were calculated as the rate of increase of total tunnel length. For 3 other shrimps, the level of the sediment surface in the cuvette was drawn daily on transparencies, starting directly after introduction of the shrimp to a cuvette. Amounts of expelled sediment were obtained by multiplying each area between 2 successive sediment levels with the cuvette width.

Grain size and organic content of sediment processed by Callianassa subterranea were quantitatively compared with unprocessed sediment samples. Samples of expelled sediment and of sediment lining the burrows were taken in duplicate from burrows of 6 single $C$. subterranea residing in 101 containers. Sediment expelled by the shrimps was collected using home-made sediment traps (Fig. 1) placed on burrow openings directly after an opening was discovered during daily inspections. Sediment lining the burrows was sampled by scraping off a thin (about $0.5 \mathrm{~mm}$ ) layer of the tube walls during dissection of the burrows at the end of the experimental period ( 4 to $6 \mathrm{wk}$ ).

Expelled sediment was analyzed at the end of the experiments after removal from the 3 cuvettes by suction. The accumulated sediment was removed in 4 portions corresponding to 4 periods with relatively high expulsion activity. The periods could be reconstructed from the series of surface level drawings on the transparencies.

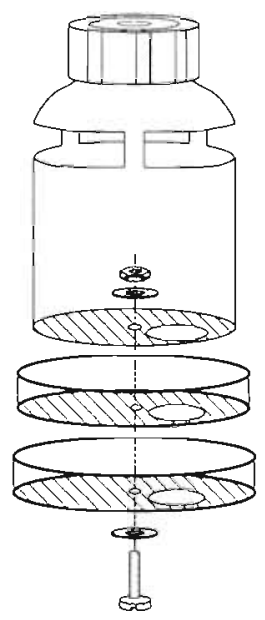

Fig. 1 Home-made sediment trap used to trap expelled sediment from the openings of Callianassa subterranea burrows. The trap is composed of a $250 \mathrm{ml}$ jar (polyethene), a petri dish, and a petrn dish lid (both polystyrene) held together with a small stainless steel bolt with nut. An opening in the bottom of the jar was set in line with openings in the dishes before placing the trap. The trap was closed prior to removal by turning one dish with respect to the other
In a separate experiment, the seawater was enriched continuously with a concentrated suspension of ground algal and zooplanktonic material. The rate of enrichment was about $1.8 \mathrm{~g}$ dry w $\mathrm{m}^{-2} \mathrm{~d}^{-1}$. This level roughly equals an algal spring bloom in the sampling area, estimated at $1.64 \mathrm{~g} \mathrm{C} \mathrm{m}^{-2} \mathrm{~d}^{-1}$ (Bak et al. 1991). Changes in the sediment composition caused by the burrowing and feeding activities of Callianassa subterranea were quantified by comparing grain size distributions and organic contents of expelled sediment and burrow lining with unprocessed samples. Changes in the composition of expelled sediment in time were analyzed following procedures identical to those used during the experiment with normal seawater.

Grain size distributions were determined in percentages of dry weight per grain size class. Sediment subsamples were washed through an 8 -step fractioning column with filters of $300,150,70,30,12,5,1.2$ and $0.7 \mu \mathrm{m}$ pore size successively. The filters were dried for $24 \mathrm{~h}$ at $60^{\circ} \mathrm{C}$ and weighed to the nearest $0.0001 \mathrm{~g}$ before and after fractioning. Organic contents of sediment sub-samples in percentages of dry weight were calculated from differences in dry weight before and after combustion at 480 to $500^{\circ} \mathrm{C}$ for $3.5 \mathrm{~h}$ (Cadee 1984).

\section{RESULTS}

\section{Burrow architecture}

An artist's impression of a typical burrow of Callianassa subterranea from the central North Sea is shown in Fig. 2 and is based on burrows established under constant laboratory conditions. Burrows of $C$. subterranea (body length $=3$ to $4 \mathrm{~cm}$ ) have a stereotypical architecture. From the outside, a burrow is characteristically identified by 1, 2, or more (on average $1.1 \pm 0.6$ ) volcano-shaped mounds with holes in the top, and 1 to 4 (on average $2.2 \pm 1.2$ ) holes in the flat sediment surface. These are sometimes funnel shaped. Occasionally, a hole is found near the base of the slope of a mound. The subterranean part of the burrows consists in general of a number of vertical shafts connected to the openings at the surface. Most of the shafts have the same diameter as the inhabiting $C$. subterranea $(8.0 \pm 1.5 \mathrm{~mm})$. Usually a twining shaft about half as narrow as the other shafts is connected to a smooth mound at the sediment surface. At their lowest points, all shafts are connected to spherical chambers interconnected by a network of horizontal and oblique tunnels with additional spherical chambers. Some of the tunnels are deadends. The twining shaft running down from the smooth mound shows an S-bend at its connection to 


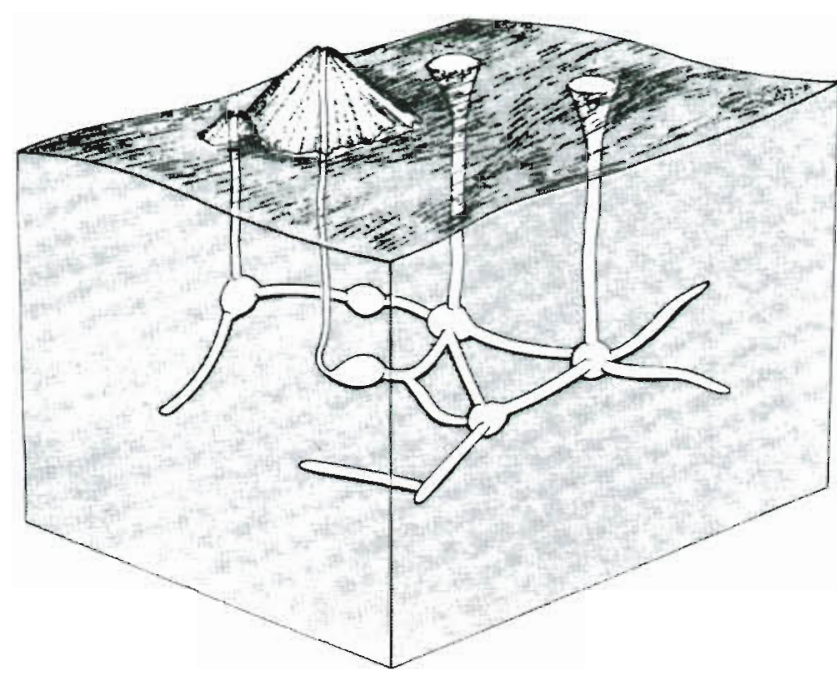

Fig. 2. Diagram showing a typical burrow of Callianassa subterranea in small containers under laboratory conditions generalized for a C. subterranea of average size $(3$ to $4 \mathrm{~cm}$ total length). Traces of other animals and artefacts due to the container walls are left out. Overall dimensions of burrow: 15 $\times 18 \mathrm{~cm}$ bottom surface area, depth 20 to $25 \mathrm{~cm}$ (sediment block dimensions: $\mathrm{h}=30, \mathrm{w}=35, \mathrm{l}=40 \mathrm{~cm}$ )

the side of an ellipsoid chamber The central part of the burrow network usually remains unchanged, whereas the more peripheral parts are reconstructed regularly.

\section{Burrow development}

New burrows are excavated following a stereotypical procedure (see Fig. 3). First a small funnel-shaped pit is excavated. This is the starting point of the first vertical shaft. During this first excavation stage, the animal loosens and lifts up some sediment, transports it to the surface walking backwards, and drops it near the funnel. This process is repeated until shaft plus funnel are about twice the length of the animal (Fig 3A). Then the lowest part of the shaft is widened and transformed into a spherical chamber As soon as the animal is able to turn in this chamber, it starts to narrow the funnel with sediment from the turning chamber until it has the same diameter as the shaft (Fig. 3B). The animal narrows the funnel from below. After this stage, the animal only appears at the sediment surface for dumping sediment.

During the next stage, a tunnel is excavated sidewards or obliquely downwards from the turning chamber. From there it gradually curves upwards until it penetrates the sediment surface, completing a $U$ shaped tube. The sediment excavated during this operation is dumped around the first opening, forming a granular mound (see Fig. 3C). From the deepest part of the U-tube a second tunnel is excavated, again at an oblique angle downwards before it gradually curves upwards until the sediment surface is reached. Usually, the excavated sediment is transported directly to the surface. Sometimes, however, it is dropped in the
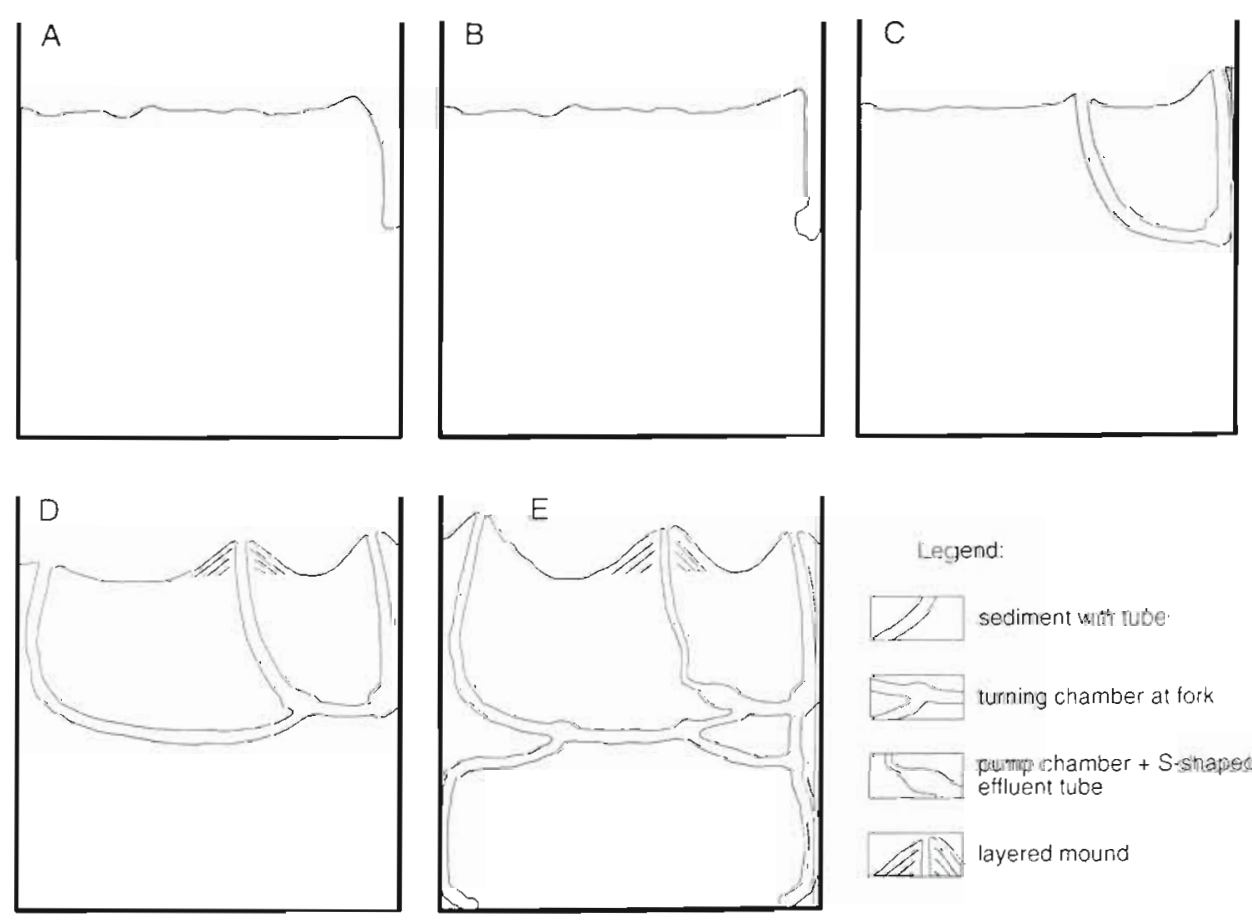

Legend:

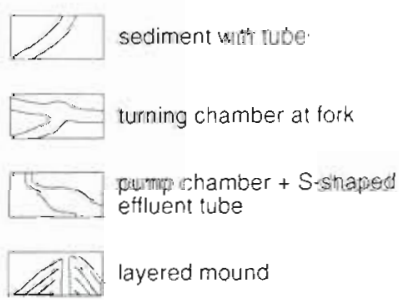

Fig. 3. Excavation pattern of a new Callianassa subterranea burrow in 5 distinct stages, for an animal of average length (ca $35 \mathrm{~mm}$ ) in a $30 \times 30 \times 0.9 \mathrm{~cm}$ cuvette. See 'Methods' 
Table 1 Callianassa subterranea. Average excavation velocity (AEV: $m m$ tunnel length $\mathrm{h}^{-1} \pm \mathrm{SD}$ ) and average burrowing time per burrow section ( $\mathrm{h} \pm \mathrm{SD}$ ) during burrow construction, from transparency drawings of burrows during development of 5 C. subterranea in cuvettes

\begin{tabular}{|lcc|}
\hline Burrow section & AEV $\left(\mathrm{mm} \mathrm{h}^{-1}\right)$ & Burrowing time $(\mathrm{h})$ \\
\hline Vert. tube & $23.4 \pm 6.0$ & $2.1 \pm 0.7$ \\
Turning chamber & $17.4 \pm 9.6$ & $1.5 \pm 1.0$ \\
1st U tube & $9.0 \pm 3.6$ & $18.4 \pm 3.7$ \\
2nd U tube & $5.6 \pm 1.8$ & ca 21.7 \\
\hline
\end{tabular}

U-shaped tube, loosened, and then pumped to the surface through the second opening, adding a thin layer to the smooth mound (Fig. 3D).

Once the 'double-U'-shaped burrow is completed, a number of individually different extension configurations can be observed. Often a new branch is started at the lowest point of the second $U$. The first vertical shaft is frequently excavated deeper and then interconnected horizontally to the second U. Fig. 3E shows one of the possible extensions of the basic burrow form.

\section{Burrowing velocities}

The initial stages of burrow formation are always carried out at higher excavation velocities, expressed as the increase of total tunnel length per hour, than the later ones (Table 1, Fig. 4).

The total length of the tunnel system ( L burrow $_{\text {in }} \mathrm{mm}$ ) as a function of time (in hours), as in Fig. 3, can be described by the following equation:

$$
\mathrm{L}_{\text {burrow }}=a\left(1-\mathrm{e}^{-b \times \text { ume }}\right)
$$

This function runs asymptotically to its maximum value $a$. The variation in our data could be explained for $94 \%$ with $a=$ $452(\mathrm{SD}=16)$ and $b=0.028(\mathrm{SD}=0.002)$ $(\mathrm{p} \ll 0.001)$. The average total tunnel length for burrows in cuvettes after about $14 \mathrm{~d}$ is therefore $452 \pm 16 \mathrm{~mm}$.

\section{Expulsion rates and the effects of POM enrichment}

The data on volume of expelled sediment from the experiments in normal seawater indicate that the experimental Callianassa subterranea show individually different patterns of excavation (Fig. 5, dashed lines). The total volumes of expelled sediment per individual after about $23 \mathrm{~d}$
(550 h), however, did not differ substantially. The data compare less well above $23 \mathrm{~d}$ due to the very high expulsion activity of 1 of the animals. This lasted $2 \mathrm{~d}$, and was probably induced by a small burrow collapse. The average expulsion rate after $1028 \mathrm{~h}$, however, hardly differs from that after $550 \mathrm{~h}$ (Table 2).

The sediment expulsion data from the experimental animals in the enriched seawater system show on average about the same results (Fig. 6, dashed lines). The expulsion is initially high and varies during the experimental period, as do the expulsion period lengths. The average expulsion rate of the animals in the enriched system does not differ much from the animals in the normal seawater system (Table 2), although it is significantly lower ( $t$-test, $p<0.05)$. However, when accounting for effects of high initial expulsion rates, as expressed in the intercept (b) in Table 2 , the differences are minimal and not significant.

The curves for the individual animals in the nonenriched as well as in the enriched system indicate variations in expulsion activity, reflected in the average expulsion rates (Figs, $5 \& 6$, thin lines). This suggests periodicity in sediment expulsion activity.

\section{Sediment composition and the effects of POM enrichment}

Grain size analysis showed that the classes 150 to $70 \mu \mathrm{m}(72 \%, \mathrm{SD}=6 \%, \mathrm{n}=12)$ and 30 to $12 \mu \mathrm{m}(16.4 \pm$ $4.9 \%$ ) and to a lesser extend the class 70 to $30 \mu \mathrm{m}$ $(6.1 \pm 2.6 \%)$, represented most of the dry mass in unprocessed sediment. The sediment composition data from the experiments comparing non-enriched and

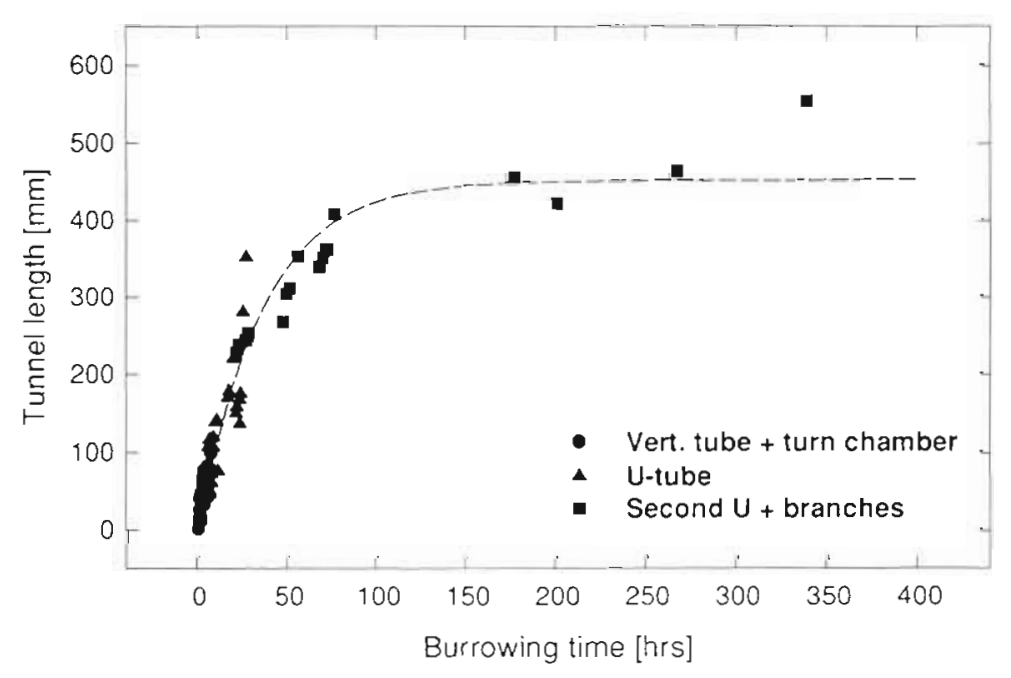

Fig. 4. Total tunnel length (mm) vs total time burrowed for Callianassa subterranea, all 69 data points from transparency drawings of 5 shrimps in cuvettes 


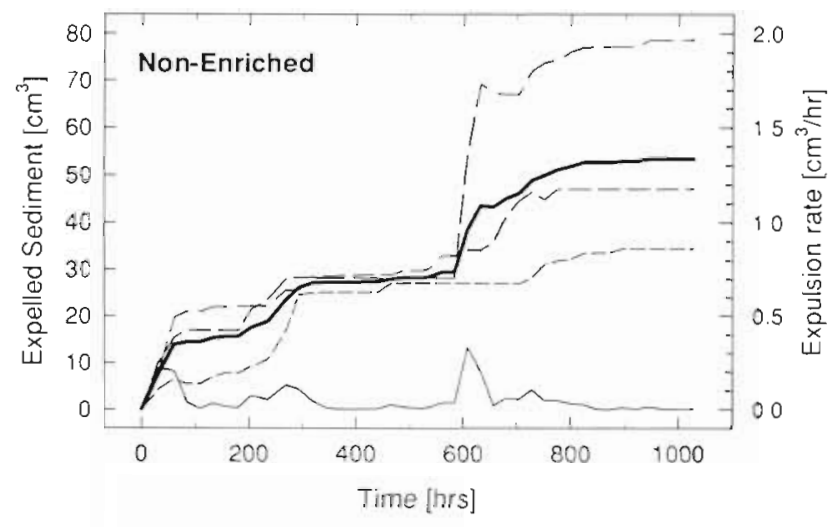

Fig. 5. Expelled sediment (accumulated) vs time as calculated from sediment surface level drawings and cuvette widths for 3 individual Callianassa subterranea in a normal seawater system. The thick line shows the average amount of expelled sediment, the thin line the average expulsion rate

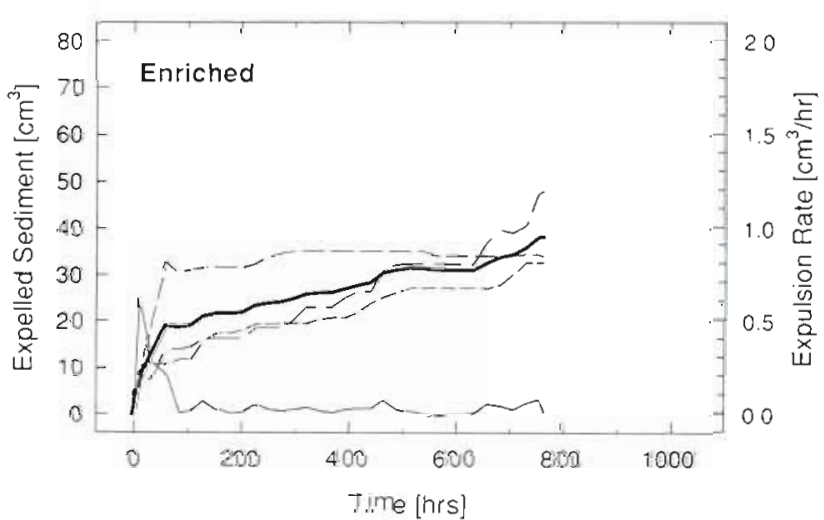

Fig. 6. Expelled sediment volume (accumulated) vs time as calculated from sediment surface level drawings and cuvette widths for 3 individual Callianassa subterranea in an enriched seawater system. The thick line shows the average amount of expelled sediment, the thin line the average expulsion rate

enriched systems did not show significant changes in the grain-size distributions of burrow lining or expelled sediment compared to unprocessed sediment, which otherwise could have indicated a difference in sediment processing by the inhabiting Callianassa subterranea due to enrichment. Also no significant trend was recognizable in the organic content of burrow lining or expelled sediment compared to unprocessed sediment, which otherwise could have indicated the burrow acting as a trap for POM (Table 3). Expelled sediment shows a significantly higher organic content than unprocessed sediment in the non-enriched as well as the enriched system, which might indicate that this well aerated sediment attracts micro-organisms.
Sediment expelled by the animals in the cuvettes was removed according to 4 periods as reconstructed from the sediment surface level drawings (see Figs. 5 \& 6, expulsion rates): Day 1 and 2, Days 3 to 12, Day 13 to 33 and Days 34 to 43 . Although some significant differences were found within some of the size classes ( $t$ test, $\mathrm{p}<0.05$ ), no obvious patterns or significant trends in the grain-size distributions or organic contents in time were found

\section{DISCUSSION}

In all Callianassa subterranea burrows studied, a double- or multiple- U-shaped structure was recognized. The shrimps usually excavate a double $U$ first, and extend this subsequently to a full size burrow. The double-U shape is therefore considered to be the basic burrow form.

Our observations on the burrow archilecture of Callianassa subterranea in the laboratory match to a certain extent the descriptions based on resin casts of burrows in the field or in mesocosms by Atkinson \& Nash (1985, 1990), Witbaard \& Duineveld (1989), Rowden \& Jones (1995) and Nickell \& Atkinson (1995). There are, however, differences regarding the average length of the vertical shafts, and the number of openings to the surface. We found longer shafts but fewer openings than Rowden \& Jones (1995) and than Witbaard \& Duineveld (1989), who also investigated animals from locations in the central North Sea. On the other hand we found shorter shafts and more openings than did Atkinson \& Nash (1990) and Nickell \& Atkinson (1995) for animals from Scottish muddy sea lochs. Rowden \& Jones (1995) suggest that silt content of the sediment might influence these characteristics in the burrowing style of $C$. subterranea. When comparing shaft length, number of openings and organic content (as a measure for silt content) among all sources, a few trends are recognized (Table 4). There are 2 data clusters which correspond to sampling area: the first from the central North Sea, showing shallow burrows with 3 or more

Table 2. Callianassa subterranea. Average expulsion rates $(A)$ during burrow excavation of 3 shrimp in a normal and 3 shrimp in an enriched seawater system, derived from linear regression through the average expulsion data per period (h). $\left(V_{\text {exc }}=A \times\right.$ time $+B ; V_{\text {esc }}$ is expelled volume in $\mathrm{cm}^{3}, A$ in $\mathrm{cm}^{3} \mathrm{~h}^{-1}, B$ in $\mathrm{cm}^{3}$, and time in $\mathrm{h}$ ). $\mathrm{n}$ is the number of data points per regression

\begin{tabular}{|lrccccc|}
\hline System & Period & $A \pm \mathrm{SD}$ & $B \pm \mathrm{SD}$ & $\mathrm{R}$ & $\mathrm{n}$ & $\mathrm{p}$ \\
\hline Normal & 550 & $0.045 \pm 0.004$ & $8.6 \pm 1.3$ & 0.93 & 22 & $\ll 0.001$ \\
Normal & 1028 & $0.050 \pm 0.002$ & $7.7 \pm 1.0$ & 0.97 & 43 & $\ll 0.001$ \\
Enriched & 770 & $0.040 \pm 0.004$ & $12.3 \pm 1.3$ & 0.92 & 24 & $\ll 0.001$ \\
\hline
\end{tabular}


Table 3. Organic contents in percentage of dry weight ( \pm SD) of unprocessed sediment, burrow lining, and expelled sediment from burrows of Callianassa subterranea for a normal and an enriched seawater system: 6 shrimps in separate burrows per system. Samples were taken and analyzed in duplicate $(n=12)$

\begin{tabular}{|lcc|}
\hline Sediment & Normal & Enriched \\
\hline Unprocessed & $1.8 \pm 1.0$ & $1.9 \pm 1.1$ \\
Burrow lining & $1.9 \pm 0.6$ & $2.0 \pm 0.7$ \\
Expelled & $3.0 \pm 1.2$ & $3.8 \pm 1.5$ \\
\hline
\end{tabular}

openings to the sediment surface, in sediment of relatively low organic content, and the second from the Scottish sea lochs, with deep burrows and 1 or occasionally 2 openings, in sediment of relatively high organic load. This suggests different burrowing habits in separate $C$. subterranea populations. When analyzing the results irrespective of sampling area, 2 trends are recognized which suggest intra-specific burrow plasticity depending on organic content of the sediment: the shaft length increases with organic content and the number of openings to the surface decreases with the organic content. Both trends are not significant, with correlation coefficients of $0.8(\mathrm{n}=5)$. According to Creutzberg et al. (1984) macro-endobenthic biomass of the upper layer of the seabed in the central North Sea is positively correlated to the mud content of the sediment. Higher mud contents are associated with higher macrobenthos densities. Assuming that these organisms are competing for food and/or space, C. subterranea may avoid this competition by making deeper burrows. It thereby reaches the deeper layers which are inaccessible to other, more surface dependent macrobenthic burrowers (de Wilde et al. 1984, Atkinson \& Nash 1985). Maintaining connections to the surface may take more effort when living deeper in the sediment, explaining a lower number of openings for deeper burrows. This agrees with Atkinson \& Nash (1990), who found deep burrows with 1 opening and also a shallower burrow with 4 openings during the same survey. Alternatively, due to the lower organic content of the North Sea sediments, C. subterranea may be forced to maintain a higher excavation level to satisfy its energetic needs, compared to the organically richer Scottish sediments (Rowden \& Jones 1995). This does, however, not explain the higher number of openings to the sediment surface of the North Sea burrows.

The Callianassa subterranea we observed always displayed ventilation behaviour and also pumped sediment to the surface (see also Stamhuis et al. 1996). Both these activities require at least 1 inhalant and 1 exhalant opening. All burrows we studied had at least 2 openings to the sediment surface. The tiny exhalant tubes might have been overlooked by Atkinson \& Nash (1990) and Nickel \& Atkinson (1995) because they close after the inhabiting animal has pumped sediment to the surface. These thin partly closed off tubes are difficult to penetrate with viscous resin and hardly show up in the casts (see also Witbaard \& Duineveld 1989, Rowden \& Jones 1995), but were found in all burrows in our laboratory setup.

The shape of openings at the sediment surface depends on the burrowing style of the inhabiting Callianassa subterranea, as well as on wear over time. Older openings are often funnel shaped, larger in diameter and the funnel extends deeper than the more nozzle-like younger ones, due to small slumpings of the tube walls at the sediment surface (see also Rowden \& Jones 1995). The funnel shape is induced by the instability of surface sediment. Differences in density, elasticity and silt content between the upper seabed surface layers may have caused the irregular thistleshaped funnels observed by Atkinson \& Nash (1985, 1990) and Nickell \& Atkinson (1995). As long as an animal frequently visits an opening, it is maintained in a straight tube or nozzle shape, otherwise the opening slowly degrades to a funnel. We never observed $C$. subterranea walk or turn in a funnel, as was suggested by Atkinson \& Nash (1990), nor did Rowden \& Jones (1995). Turning in the funnel would probably induce a small avalanche causing a barrier in the tube, eventually preventing the shrimp from re-entering the burrow.

In the rare cases of spontaneous tube collapse, Callianassa subterranea removed the blockage and repaired the tube-walls. Obstructing sediment was transported to an old tube or to the surface and dumped on the rim of a mound. Sediment was also

Table 4. Number of burrow openings, average shaft lengths and organic content of the inhabited sediment observed for Callanassa subterranea in 5 different studies at 2 sites (N: North Sea; S: Scottish sea lochs). Number of observations shown in parentheses

\begin{tabular}{|lcclc|}
\hline $\begin{array}{l}\text { Openings } \\
\text { (no. } \pm \text { SD) }\end{array}$ & $\begin{array}{c}\text { Shaft length } \\
(\mathrm{cm} \pm \mathrm{SD})\end{array}$ & $\begin{array}{c}\text { Organic } \\
\text { content (\%) }\end{array}$ & Source & Site \\
\hline $5.9 \pm 1.6(10)$ & $13 \pm 3(13)$ & $1-2$ & Rowden \& Jones (1995) & $\mathrm{N}$ \\
$9.5 \pm 0.7(2)$ & $\leq 25^{\mathrm{a}}$ & $2-3^{\mathrm{d}}$ & Witbaard \& Duineveld (1989) & $\mathrm{N}$ \\
$4.2 \pm 1.2(42)$ & $25 \pm 7(81)$ & $2-3$ & This study & $\mathrm{N}$ \\
$2.3 \pm 0.5(8)$ & $65 \pm 17(8)$ & ca 6 & Nickell \& Atkinson (1995) & $\mathrm{S}$ \\
$1.2 \pm 0.8(13)$ & $44 \pm 17(28)$ & 8 & Atkinson \& Nash (1990) & $\mathrm{S}$ \\
Aumber of observations of shaft length and \% organic content not given & \\
\hline
\end{tabular}


pumped to the surface by fast pleopod movements after it was mixed with water in a special pump-chamber. (For a detailed description of the burrowing behaviour of C. subterranea, see Stamhuis et al. 1996.) The pump chamber is connected to the mound at the surface by a vertical twining shaft, which is sealed off after each pumping bout by the sediment ejected last. Every time sediment is pumped to the surface, the animal has to open the shaft by building up pressure until the plug of sediment is pushed away and the watersediment mixture from the pump-chamber is flushed out. This results in a 10 to $15 \mathrm{~s}$ volcano-like eruption from the mound opening, after which the ejected material slowly beds down on and around the mound. The narrow exhalant shaft is connected to the side of the pump chamber by a S- or coil-shaped bend of the shaft (Witbaard \& Duineveld 1989, Nickell \& Atkinson 1995, Rowden \& Jones 1995; this study). This shaft with its connection to the pump chamber evolves during early stages of burrow development from a shaft of the same diameter as the other tunnels and shafts. The initially wide shaft silts up gradually because the last sediment ejected during pumping partly falls back into the shaft. At every eruption, the water-sediment slurry meanders through the partly closed off tube, following a coiled or twining path (see also Fig 2D, E). The narrow shaft is not used for purposes other than pumping out sediment.

Callianassa subterranea maintains an extensive burrow and regularly expels sediment (Nickell \& Atkinson 1995, Rowden \& Jones 1995, Rowden et al. 1997, this study). Excavated sediment is processed during burrowing (Stamhuis et al. 1996), and only a fraction is ingested (Stamhuis pers. obs.). C. subterranea should therefore be classified as a burrowing deposit feeder. Existing thalassinid burrow classification models (Griffis \& Suchanek 1991, Nickell \& Atkinson 1995) suggest that $C$. subterranea filter feeds as well, but neither the behaviour nor the burrow architecture provides evidence for this assumption.

Burrows may provide shelter against predators. Circumstantial evidence for this assumption can be deduced from the fact that Callianassa subterranea always immediately starts to excavate a shaft when placed on the sediment surface. As soon as the shaft reaches a certain depth, the opening is narrowed and the shrimp hardly shows up on the sediment surface any more. The shaft is extended to a full burrow by excavating underneath the sediment surface. The animal only appears at the surface to dump excavated sediment.

Within a few days after initiation of a new burrow, the amount of expelled sediment reduces to almost zero. Subsequently, short periods of higher expulsion activity alternate with longer periods of low expulsion activity. These results suggest periodicity in the sediment expulsion rate, which was also found by Rowden et al. (1997). Callianassa subterranea temporarily stores sediment inside the burrow and transports it periodically to the surface. The cycle duration varies between a few days and a few weeks. A cycle usually starts with high expulsion activity, levelling off in time. The burrowing behaviour of $C$. subterranea does not show significant periodicity with cycles shorter than $72 \mathrm{~h}$ (Stamhuis et al. 1996).

On average Callianassa subterranea burrows with an expulsion rate of $0.045 \pm 0.004 \mathrm{~cm}^{3}$ sediment $\mathrm{h}^{-1}$ (at $12^{\circ} \mathrm{C}$ ). This is equivalent to $1.41 \pm 0.25 \mathrm{~g} \mathrm{dry} w \mathrm{t}$ ind. ${ }^{-1}$ $\mathrm{d}^{-1}$ using a conversion coefficient of $1.31 \pm 0.22 \mathrm{~g}$ dry wt $\mathrm{cm}^{-3}$ based on the analysis of 8 samples of expelled sediment. When extending this estimate to a yearly period for a community with an average density of 40 individuals of average size (carapace length $\approx 9 \mathrm{~mm}$, total length $\approx 35 \mathrm{~mm}$ ) per $\mathrm{m}^{2}$, the sediment turnover rate for $C$. subterranea would be $20.6 \pm 3.6 \mathrm{~kg}$ dry $w \mathrm{t}$ $\mathrm{m}^{-2} \mathrm{yr}^{-1}$. However, this estimate assumes a constant temperature of $12^{\circ} \mathrm{C}$, and a constant expulsion rate throughout the year. The actual bottom water temperature at the sampling site shows a sinusoidal annual cycle between 6 and $15^{\circ} \mathrm{C}$ (Duineveld \& van Noort 1986. Rowden et al. 1997). Regression on data from Rowden et al. (1997) reveals that the sediment expulsion rate of $C$. subterranea varies linearly between zero and maximum values in this temperature range $(\mathrm{p}<0.002)$. Our estimate of the annual sediment turnover of $C$. subterranea is $15.5 \pm 2.7 \mathrm{~kg}$ dry wt $\mathrm{m}^{-2}$ $\mathrm{yr}^{-1}$ (a layer of $1.2 \pm 0.2 \mathrm{~cm}$ ), if the linear expulsion rate variation with the annual temperature change is taken into account. This is 1.4 times the estimate of Rowden et al. (1996) but almost 5 times as high as estimated by Witbaard \& Duineveld (1.989). Witbaard \& Duineveld based their figure on the amount of sediment expelled by 4 shrimp during 1 wk. Temperature and population density effects were not taken into account. Recalculation of their data, including temperature and density effects, results in $10 \pm 5 \mathrm{~kg} \mathrm{DW} \mathrm{m}{ }^{-2} \mathrm{yr}^{-1}$

We found no evidence showing that the burrows of Callianassa subterranea function as a trap for POM, as suggested by Witbaard \& Duineveld (1989). No consistent relations were found between sediment composition, sediment expulsion rates or burrowing behaviour and POM enrichment of the overlaying water.

Acknowledgements. We thank the crews of the Research Vessels 'Aurelia' and 'Pelagia' for their assistance during the sampling trips. P. J. Geerlink replaced E.J.S. on one of the sampling trips. We acknowledge $G$. J. Cieertjes, B. Dauwe and $U$. Lenze for recording data during the burrow development experiments and $J$. J. de Wiljes for looking after the seawater systems and feeding the animals between the experiments. 


\section{LITERATURE CITED}

Atkinson RJA, Chapman CJ (1984) Resin casting: a technique for investigating burrows in sublittoral sediments. Progr Underwater Sci 9:15-25

Atkinson RJA, Nash RDM (1985) Burrows and their inhabitants. Progr Underwater Sci 10:109-115

Atkinson RJA, Nash RDM (1990) Some preliminary observations on the burrows of Callianassa subterranea (Montagu) (Decapoda: Thalassinidea) from the west coast of Scotland. J Nat Hist 24:403-413

Bak RPM, van Duyl FC, Nieuwland G, Kop AJ (1991) Benthic heterotrophic nanoflagellates in North Sea field/mesocosm bottoms and their response to sedimentation. In: van Duyl FC (ed) The applicability of mesocosms in North Sea eutrophication studies. Neth Inst Sea Res Rep 1991 5: $75-83$

Cadee GR (1984) Macrobenthos and macrobenthic remains on the Oyster Grounds, North Sea. Neth J Sea Res 18:160-178

Creutzberg F, Wapenaar P, Duineveld G, Lopez Lopez N (1984) Distribution and density of benthic fauna in the Southern North Sea in relation to bottom characteristics and hydrographic conditions. Rapp PV Reun Cons Int Explor Mer 183:101-110

de Vaugelas J (1985) Sediment reworking by callianassid mud-shrimp in tropical lagoons: a review with perspectives. Proc 5th Int Coral Reefs Congr Tahiti 6:617-622

de Wilde PAWJ, Berghuis EM, Kok A (1984) Structure and energy demand of the benthic community of the oyster ground, central North Sea. Neth J Sea Res 18(1/2): $143-159$

Duineveld GCA, van Noort GJ (1986) Observations on the population dynamics of Amphiura filiformis (Ophiuroidea: Echinodermata) in the southern North Sea and its exploitation by the dab, Limanda limanda. Neth $J$ Sea Res 20(1):85-94

Dworschak PC (1983) The biology of Upogebia pusilla [Petagna] (Decapoda, Thalassinidea) l. The burrows. PSZN I: Mar Ecol 4(1):19-43

Dworschak PC, Pervesler P (1988) Burrows of Callianassa bouvieri [Nobili 1904] from Safaga (Egypt, Red Sea) with some remarks on the biology of the species. Senckenb Marit 20:1-17

Griffis RB, Suchanek TH (1991) A model of burrow architecture and trophic modes in thalassinidean shrimps

This article was submitted to the editor
(Decapoda: Thalassinidea). Mar Ecol Prog Ser 79:171-183

Mukai H, Koike I (1984) Behaviour and respiration of the burrowing shrimps Upogebia major [de Haanl and CalLianassa japonica [de Haan]. J Crust Biol 4(2):191-200

Nickell LA, Atkinson RJA (1995) Functional morphology of burrows and trophic modes of three thalassinidean shrimp species, and a new approach to classification of thalassinidean burrow morphology. Mar Ecol Prog Ser 128 : $181-197$

Ott JA, Fuchs B, Fuchs R, Malasek A (1976) Observations on the biology of Callianassa stebbingi [Borradaille] and Upogebia littoralis [Risso] and their effect upon the sediment. Senckenb Marit 8(1/3):61-79

Rowden AA, Jones MB (1994) A contribution to the biology of the burrowing mud shrimp Callianassa subterranea (Decapoda: Thalassinidea). J Mar Biol Ass UK 74:623-635

Rowden AA, Jones MB (1995) The burrow structure of the mud shrimp Callianassa subterranea (Decapoda: Thalassinidea) from the North Sea. J Nat Hist 29:1155-1165

Rowden AA, Jones MB, Morris AW (1997) Sediment turnover estimates for the mud shrimp Calliandssa subterranea [Montagu] (Thalassinidea) and its influence upon resuspension in the North Sea. Cont Shelf Res (1n press)

Scott PJB, Reiswig HM, Marcotte BM (1988) Ecology, functional morphology, behaviour and feeding in coral- and sponge-boring species of Upogebia (Crustacea: Decapoda: Thalassinidea). Can J Zool 66:483-495

Stamhuis EJ, Reede-Dekker T, Etten Y van, Wiljes JJ de, Videler JJ (1996) Behaviour and time allocation in the burrowing shrimp Callianassa subterranea (Decapoda, Thalassinidea). J Exp Mar Biol Ecol 204:225-239

Suchanek TH (1985) Thallassinid shrimp burrows: ecological significance of species-specific architecture. Proc 5th Int Coral Reefs Congr Tahiti 5:205-210

Swinbanks DD, Murray JW (1981) Biosedimentological zonation of Boundary Bay tidal flats, Fraser River Delta, British Columbia. Sedimentology 28:201-237

Thompson RK. Pntchard AW (1969) Respiratory adaptations of two burrowing crustaceans, Callianassa californiensis and Upogebia pugettensis (Decapoda, Thalassinidea). Biol Bull 136:114-129

Witbaard R, Duineveld GCA (1989) Some aspects of the biology and ecology of the burrowing shrimp Callianassa subterranea (Montagu) (Thalassinidea) from the southern North Sea. Sarsia 74:209-219

Manuscript first received: May 31, 1996

Revised version accepted: February 25, 1997 